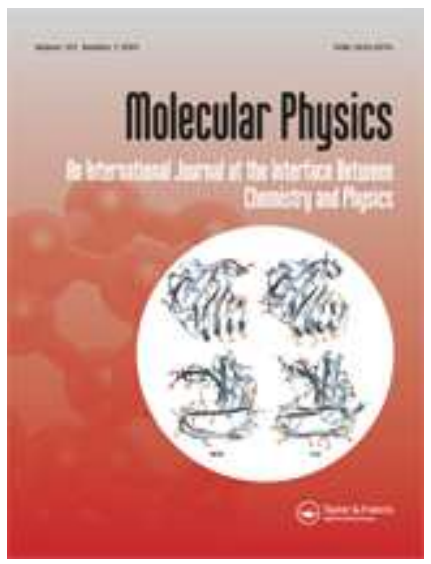

\title{
Theoretical Study of the Helio Hydrogen Cyanide Dication $\mathrm{HeCNH}^{\wedge}\{2+\}$
}

\begin{tabular}{|c|c|}
\hline Journal: & Molecular Physics \\
\hline Manuscript ID: & TMPH-2009-0203 \\
\hline Manuscript Type: & Full Paper \\
\hline $\begin{array}{l}\text { Date Submitted by the } \\
\text { Author: }\end{array}$ & 06-Jul-2009 \\
\hline Complete List of Authors: & $\begin{array}{l}\text { Wilson, Stephen; Oxford University, PTCL; Comenius University, } \\
\text { Chemical Physics } \\
\text { Hubac, Ivan; Comenius University, Chemical Physics } \\
\text { Mach, Pavol; Comenius University, Chemical Physics } \\
\text { Uhlar, Milan; Opava University, Institute of Physics }\end{array}$ \\
\hline Keywords: & $\begin{array}{l}\text { helio hydrogen cyanide, } \mathrm{HeCNH}^{\wedge}\{2\} \text {, inert gas molecules, } \\
\text { interstellar molecules, MP2, } \operatorname{CCSD}, \operatorname{CCSD}(T), C A S S C F, C A S P T 2\end{array}$ \\
\hline \multicolumn{2}{|c|}{$\begin{array}{l}\text { Note: The following files were submitted by the author for peer review, but cannot be converted } \\
\text { to PDF. You must view these files (e.g. movies) online. }\end{array}$} \\
\hline LaTeX_file.tex & \\
\hline
\end{tabular}

\section{s ScholarONE \\ Manuscript Central}




\title{
Page 1 of 18

Molecular Physics

Vol. 00, No. 00, Month 200x, 1-8

\section{RESEARCH ARTICLE}

\section{Theoretical Study of the Helio Hydrogen Cyanide Dication $\mathrm{HeCNH}^{2+}$}

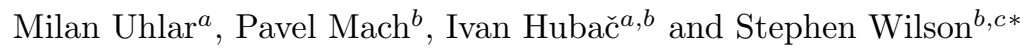 \\ ${ }^{a}$ Institute of Physics, Faculty of Philosophy and Science, Silesian University in Opava, \\ Bezrucovo nam. 13, 746 01 Opava, Czech Republic; ${ }^{b}$ Department of Chemical Physics, \\ Faculty of Mathematics, Physics and Informatics, Comenius University, 84215 \\ Bratislava, Slovakia; ${ }^{c}$ Theoretical Chemistry Group, Physical and Theoretical Chemistry \\ Laboratory, University of Oxford, South Parks Road, Oxford, OX1 3QZ, United Kingdom
}

(21 June 2009)

\begin{abstract}
The structure and stability of the helio hydrogen cyanide molecular ion, $\mathrm{HeCNH}^{2+}$, is investigated by standard quantum chemical methods. Single reference calculations are carried out using second order perturbation theory (MP2), the coupled cluster expansion in the CCSD approximation, and the hybrid approach using a perturbative estimate of the triple excitation energy component designated $\operatorname{CCSD}(\mathrm{T})$. Multireference calculations using a complete active space (CASSCF) and a second order perturbation theory estimate of correlation effects (CASPT2) are reported.
\end{abstract}

Keywords: helio hydrogen cyanide, $\mathrm{HeCNH}^{2+}$, inert gas molecules, interstellar molecules, MP2, CCSD, CCSD $(\mathrm{T})$, CASSCF, CASPT2

\section{Introduction}

Of the various techniques available for the study of matter on a molecular scale, computational quantum chemistry has particular strengths and weakness. In principle, $a b$ initio quantum chemical methods can be applied to any grouping of atoms irrespective of whether they form a stable molecule or not. This has been found invaluable, for example, in the study of interstellar radicals and ions particularly in cases where the species under investigation are not stable in the terrestrial laboratory[12] $]^{1}$.

Radicals, such as the cyanoethynyl and the butadiynyl radicals[7], and ions, such as the thioformyl ion[8], have been identified in interstellar environments[9-11] on the basis of ab initio quantum chemical calculations prior to their observation on Earth. The principle weakness of $a b$ initio quantum chemical methods is the rapid increase in the complexity of the associated computations with the number of atoms and/or number of electrons in the system under study. The most abundant elements in the universe are those of the light atoms hydrogen, helium, carbon, nitrogen and oxygen. Contemporary non-relativistic quantum chemical methods can support accurate calculations on small molecular systems containing these light atoms. Helium is the second most abundant element in the universe and this led Wilson and Green[12] to suggest that, in spite of it being the most inert of the

\footnotetext{
*Corresponding author. Email: quantumsystems@gmail.com

${ }^{1}$ See, for example, $[2-6]$ for recent reviews on the subject of molecules in space.

ISSN: 0040-5167 print/ISSN 1754-2278 online

(C) 200x Taylor \& Francis

DOI: $10.1080 / 0040516 Y Y x x x x x x x x$

http://www.informaworld.com
} 
inert gases, helium-containing ions could have sufficient stability to be observed in the interstellar medium. In particular, these authors suggested the $\mathrm{HeCN}^{+}$ion as a candidate since the cyano-group ensures that the system has a large dipole moment to enhance detection by radio-astronomy. Although the $\mathrm{HeCN}^{+}$ion has not been found in space, it has nevertheless emerged from subsequent studies that simple ions containing helium have a rich chemistry (see, for example, the recent review by Grandinetti[13]).

The structure and stability of helium-containing polyatomic cations have been investigated by a number of authors [12, 14-20]. In a paper published in 1999, Olah et al[19] found the helionitronium trication, $\mathrm{HeNO}_{2}^{3+}$, to be unusually stable. These authors drew this conclusion from second order many-body perturbation theory calculations. However, subsequent work by Eisfeld and Franciso[20] using multireference configuration interaction demonstrated that the wave function for this systems may have "extreme multireference character".

In this paper, an $a b$ initio quantum chemical study of the structure and stability of the ground state of the $\mathrm{HeCNH}^{2+}$ ion is presented. The previous work summarized above points to the need for a thorough description of electron correlation effects including the use a multireference formalism. It is well known that when truncated, as it must be in practical applications, multireference configuration interaction suffers from non-linear scaling with particle number (i.e. lack of extensivity). Although an a posteriori correction of the type suggested by Davidson[21-25] for the single reference case can be applied, this is only approximate. On the other hand, multireference many-body methods (i.e. perturbation theory and cluster expansions) are plagued by the 'intruder state problem' which can impair or even destroy convergence. Furthermore, it should be emphasised that, for novel species such as the ion under investigation here, the algebraic approximation must be implemented in a sequence of basis sets in order to explore the basis sets dependence of the electron correlation calculations and to estimate the complete basis set limit.

Most contemporary applications of quantum mechanics to the molecular electronic structure problem use what is termed the 'theoretical model chemistry' approach championed by Pople and his coworkers[26]. A composite theoretical model chemistry involves a series of compromises[28, 29], based on the methods and basis sets employed and dictated by the computing resources available. Systematic comparison of the results supported by a given model with corresponding data derived from experiment may give that model a predictive capability in situations where experiment is difficult or impossible, or simply too expensive. However, when quantum chemical methods are used to study novel systems such as that investigated here the highest level of theory and basis which is feasible for a system of this size should be employed.

$\mathrm{HeCNH}^{2+}$ is a 14-electron system which is isoelectronic with the well characterised HCN molecule. The carbon and nitrogen atoms each have a $1 s^{2}$ core leaving a total of 10 'valence' electrons. Of all the elements helium has the highest ionization potential $(24.587 \mathrm{eV})$ and the lowest polarizability $\left(0.205 \mathrm{~A}^{-3}\right)$ [30] and forms very few neutral molecular species. Although helium will form clusters $\mathrm{He}_{n}, n \geq 2,[31]$ only a few neutral partners, such as $\mathrm{Hg}[32,33]$ or endohedral $\mathrm{C}_{60}$ complexes[34, 35] are able to fix helium. A few compounds such as OBeHe[36] and RNBeHe[37] have been predicted to be stable in theoretical studies. Grandinetti[13] observes that for cationic binding partners "the capability of fixing helium dramatically increases, and numerous singly-and multiply-charged cations containing one or more helium atoms have been experimentally or theoretically investigated". 


\section{Page 3 of 18 \\ Molecular Physics}

\section{Methodology}

Calculations were performed for the ground state of the $\mathrm{HeCNH}^{2+}$ cation using 'standard' ab initio quantum chemical methods. Specifically, we employed (i) single reference second order many-body perturbation theory in its Møller-Plesset form, MP2; (ii) the coupled cluster expansion including single and double excitations from a single reference function, CCSD; (iii) CCSD with a perturbative estimate of the triple excitation energy component, $\operatorname{CCSD}(\mathrm{T}) ;(i v)$ multiconfiguration self-consistent field theory in the complete active space self-consistent field form, CASSCF; $(v)$ second order perturbation theory based on a CASSCF reference function, CASPT2.

The algebraic approximation[38, 39] was realized using the correlation consistent basis sets developed by Dunning and his coworkers[46]. Specificially, we employed a polarized valence basis set of 'quadruple zeta' quality designated $c c-p V Q Z$. The molecular basis set contains a total of 201 primitive Gaussian-type functions which are contracted to give a set of 170 contracted Gaussian-type functions. The basis sets where taken from the MOLCAS library and the GAUSSIAN and can be found on the EMSL Basis Set Library at https://bse.pnl.gov/bse/portal.

The MP2, CCSD, CCSD (T), CASSCF and CASPT2 calculations were carried out using the MOLCAS 7.2 program package[41]. Geometry optimizations for the $\operatorname{CCSD}(\mathrm{T})$ model were performed with the GAUSSIAN03 program package[43]. The MOLDEN 4.6 package[42] was used to visualize the results.

Single reference self-consistent field calculations gave the following ground state configurations

$$
\begin{aligned}
& \text { linear: } 1 \sigma^{2} 2 \sigma^{2} 3 \sigma^{2} 4 \sigma^{2} 5 \sigma^{2} 1 \pi^{4} \\
& \text { non-linear: } 1 a^{\prime 2} 2 a^{\prime 2} 3 a^{\prime 2} 4 a^{\prime 2} 5 a^{\prime 2} 6 a^{\prime 2} 1 a^{\prime \prime 2} \\
& C_{s} \text { symmetry: } 1 a^{\prime 2} 2 a^{\prime 2} 3 a^{\prime 2} 4 a^{\prime 2} 5 a^{\prime 2} 6 a^{\prime 2} 1 a^{\prime \prime 2}
\end{aligned}
$$

Geometry optimization was carried out for the MP2 model and the optimized geometries thus obtained were employed in $\operatorname{CCSD}$ and $\operatorname{CCSD}(\mathrm{T})$ calculations the results of which were labelled $\mathrm{CCSD} / \mathrm{MP} 2$ and $\operatorname{CCSD}(\mathrm{T}) / \mathrm{MP} 2$, respectively. Geometry optimization was also carried out for the $\operatorname{CCSD}(\mathrm{T})$ model.

The multireference calculations employed a complete active space of 12 orbitals to describe the 10 valence electrons, designated CASSCF(10e/12o). For the linear goemetry, the active space was constructed from three bonding orbitals of $\sigma$ symmetry and two bonding orbitals of $\pi$ symmetry together with two non-bonding orbitals of $\pi$ symmetry and five non-bonding orbitals of $\sigma$ symmetry. Geometry optimization was carried out both for the CASSCF model and for the CASPT2 model.

For both the single reference and multireference cases, the potential energy surfaces were explored and stationary points identified and characterized as a global minimum, local minima and transition states.

The dissociation of the structures determined in this way into fragments of the type $\mathrm{AB}^{+}+\mathrm{CD}^{+}$was studied by performing calculations for the supersystem $\mathrm{AB}^{+}$ ... $\mathrm{CD}^{+}$with the distance between the two fragments set to a large value $(9000$ A). Other coordinates were optimized using 15 active orbitals to describe the 10 valence electrons in the CASSCF model. Then a second order perturbation theory calculations using the geometry so determined was carried out using the CASPT2 method. 


\section{Results}

A summary of the results of the quantum chemical calculations employing single reference models is collected in Table 1 . Total electronic energies, correlation energies and structural parameters, i.e. bond lengths, bond angles and dihedral angles, are presented for the MP2, CCSD and $\operatorname{CCSD}(\mathrm{T})$ models. The MP2 model was used to explore the potential energy surface and a total of seven stationary points were identified. In addition to a global minimum, three local minima were found as well as three transition states. The geometries corresponding to these stationary points are shown in Figure 1. The global minimum corresponds to the linear structure $\mathrm{HeCNH}^{2+}$ shown in Figure 1(a) and labelled $L$. One of the local minima in the potential energy surface is associated with the non-linear structure $\mathrm{HeNCH}^{2+}$ in Figure 1(b) and labelled $N$ and the other two local minima correspond to trigonal pyramidal configurations, labelled $T 1$ and $T 2$, and shown in Figure 1(c) and (d) with the formulae $\mathrm{NC}(\mathrm{He}) \mathrm{H}^{2+}$ and $\mathrm{CN}(\mathrm{He}) \mathrm{H}^{2+}$, respectively. The three transition states corresponding to the formulae $\mathrm{NC}(\mathrm{He}) \mathrm{H}^{2+}, \mathrm{NC}(\mathrm{He}) \mathrm{H}^{2+}$ and $\mathrm{NC}(\mathrm{He}) \mathrm{H}^{2+}$, respectively, are displayed in Figure 1(e), $(f)$ and $(g)$. The energies for the CCSD and $\operatorname{CCSD}(\mathrm{T})$ models presented in Table 1 were calculated at the geometries determined by using the MP 2 model and are labelled $E_{\mathrm{CCSD} / \mathrm{MP} 2}$ and $E_{\mathrm{CCSD}(\mathrm{T}) / \mathrm{MP} 2}$. Energies obtained by optimizing the geometries for the $\operatorname{CCSD}(\mathrm{T})$ model are labelled $E_{\mathrm{CCSD}(\mathrm{T})}$. The $t 1$ diagnostic suggested by Lee et al $[44,45]$ was used in the $\operatorname{CCSD}(\mathrm{T})$ calculations to determine whether a single reference wave function is adequate for each of the geometries examined. For the $\operatorname{CCSD}(\mathrm{T})$ calculations in which the geometry was optimized within that model, the $t 1$ diagnostic took the values 0.0138 and 0.0352 for the $L$ and $N$ structures, repectively. For the $T 1$ and $T 2$ geometries, the $t 1$ diagnostic was 0.0261 and 0.0267 , respectively, whilst for the transition states $T S 1, T S 2, T S 3$, the values recorded were $0.0226,0.0835$ and 0.0322 . It can be seen that of the different structures studied, the $L$ is best described by the $\operatorname{CCSD}(\mathrm{T})$. Reasonably low values of the $t 1$ diagnostic $(\leq 0.03)$ were measured for both of the trigonal pyramidal structures and the transition state TS1. However, for the nonlinear geometry and the TS2 and TS3 transition states substantial multireference character is indicated. For these geometries, the single reference coupled cluster theory $\operatorname{CCSD}(\mathrm{T})$ is not as reliable as it is for the other structures.

The results of the quantum chemical calculations employing multi-reference models are summarized in Table 2.

In Table 3, the calculated total energies, in $\mathrm{kJ} \mathrm{mol}^{-1}$, associated with the structures displayed in Figure 1 are shown relative to the most stable structure, the linear configuration $L$. In this Table it can be seen that the linear structure $L$ $\mathrm{HeCNH}^{2+}$ is the most stable with other structures having energies lying $\sim 200 \mathrm{~kJ}$ $\mathrm{mol}^{-1}$ or more above. Of the five different models employed in the present study, the largest differences in the calculated total energies occur for the MP2 model. For some of the structures studied the difference between the energies supported by the CCSD and CASPT2 models is quite large. For these structures some of cluster amplitudes were found to be larger than $\sim 0.1$.

Three transition states were identified on the potential energy surface which correspond to the migration of the $\mathrm{H}$ or He atom from $\mathrm{CN}$ to NC. These transition states lie between the local minima and the global minimum.

Dissociation energies corresponding to the following decay schemes were calcu- 


\section{Page 5 of $18 \quad$ Molecular Physics}

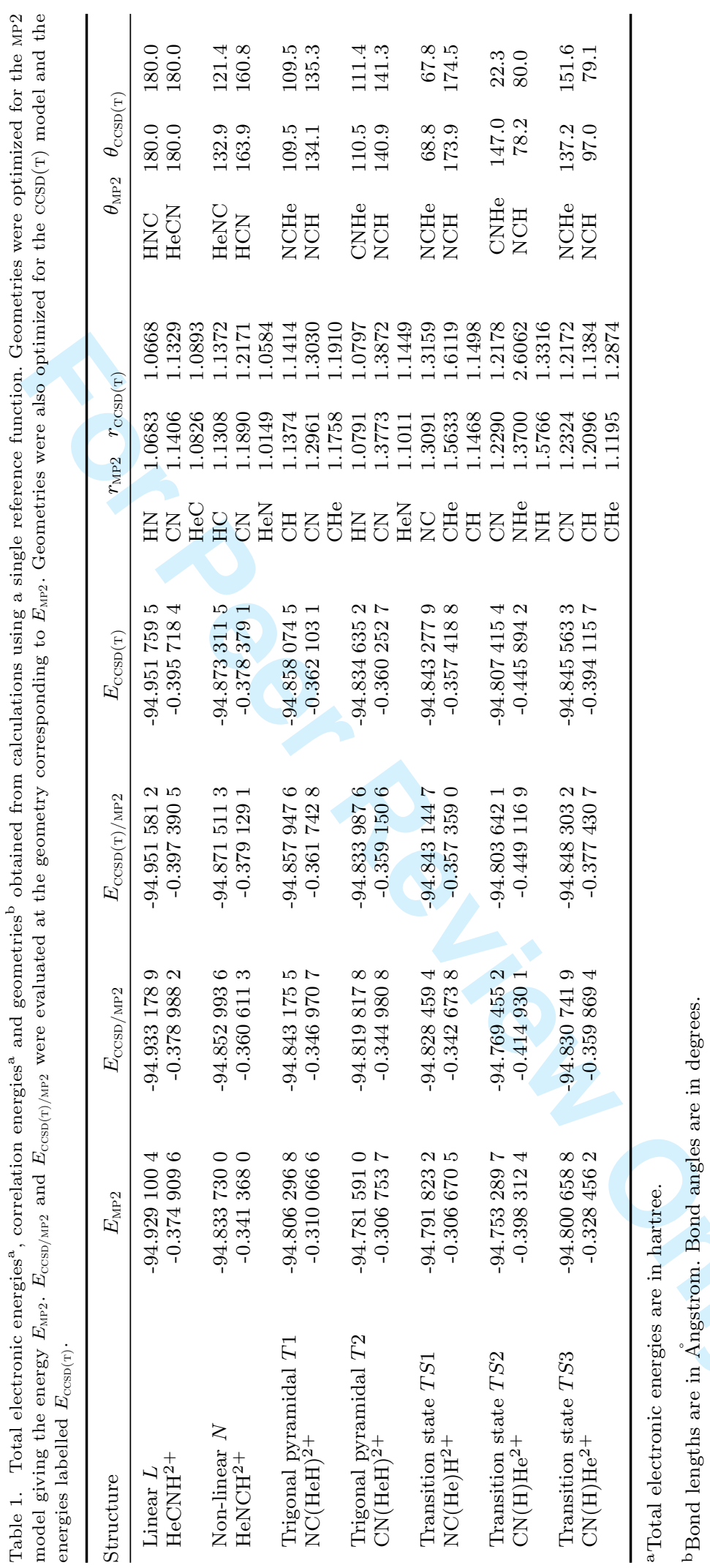


6

Table 2. Total electronic energies ${ }^{\mathrm{a}}$ and geometries $^{\mathrm{b}}$ obtained from calculations using a multi-reference function. Geometries were optimized for the CASSCF model giving the energy $E_{\mathrm{CASSCF}}$. Geometries were also optimized for the $E_{\mathrm{CASPT} 2}$ model giving the energy $E_{\mathrm{CASPT} 2}$.

\begin{tabular}{|c|c|c|c|c|c|c|c|c|}
\hline \multirow{2}{*}{$\frac{\text { Structure }}{\text { Linear } L}$} & \multirow{2}{*}{$\frac{E_{\mathrm{CASSCF}}}{-94.7723331}$} & $E_{\text {CASPT2 }}$ & \multicolumn{3}{|c|}{$r_{\mathrm{CASSCF}} \quad r_{\mathrm{CASPT} 2}$} & \multicolumn{3}{|c|}{$\theta_{\mathrm{CASSCF}} \quad \theta_{\mathrm{CASPT} 2}$} \\
\hline & & -94.9363202 & $\mathrm{NH}$ & 1.0701 & 1.0665 & $\mathrm{CNH}$ & 180.0 & 180.0 \\
\hline \multirow[t]{2}{*}{$\mathrm{HeCNH}^{2+}$} & & & $\mathrm{CN}$ & 1.1360 & 1.1337 & $\mathrm{HeCN}$ & 180.0 & 180.0 \\
\hline & & & $\mathrm{HeC}$ & 1.0989 & 1.0889 & & & \\
\hline Non-linear $N$ & -94.6929172 & -94.8553807 & $\mathrm{HC}$ & 1.1422 & 1.1366 & $\mathrm{HeNC}$ & 121.0 & 121.1 \\
\hline \multirow[t]{2}{*}{$\mathrm{HeNCH}^{2+}$} & & & $\mathrm{CN}$ & 1.2209 & 1.2189 & $\mathrm{HCN}$ & 160.1 & 160.4 \\
\hline & & & $\mathrm{HeN}$ & 1.0772 & 1.0606 & & & \\
\hline Trigonal pyramidal $T 1$ & -94.6850509 & -94.8394816 & $\mathrm{CH}$ & 1.1438 & 1.1422 & $\mathrm{NCHe}$ & 108.1 & 110.7 \\
\hline \multirow[t]{2}{*}{$\mathrm{NC}(\mathrm{HeH})^{2+}$} & & & $\mathrm{CN}$ & 1.3113 & 1.3014 & $\mathrm{NCH}$ & 137.8 & 133.7 \\
\hline & & & $\mathrm{CHe}$ & 1.2219 & 1.1843 & & & \\
\hline Trigonal pyramidal $T 2$ & -94.6529726 & -94.8144955 & $\mathrm{HN}$ & 1.0870 & 1.0811 & $\mathrm{CNHe}$ & 110.0 & 113.9 \\
\hline \multirow[t]{2}{*}{$\mathrm{CN}(\mathrm{HeH})^{2+}$} & & & $\mathrm{CN}$ & 1.3891 & 1.3855 & $\mathrm{NCH}$ & 143.4 & 139.4 \\
\hline & & & $\mathrm{HeN}$ & 1.1957 & 1.1714 & & & \\
\hline$T S 1$ & -94.6723976 & -94.8244459 & $\mathrm{NC}$ & 1.3261 & 1.3163 & $\mathrm{NCHe}$ & 67.9 & 70.0 \\
\hline \multirow[t]{2}{*}{$\mathrm{NC}(\mathrm{He}) \mathrm{H}^{2+}$} & & & $\mathrm{CHe}$ & 1.6943 & 1.6044 & $\mathrm{NCH}$ & 174.9 & 174.2 \\
\hline & & & $\mathrm{CH}$ & 1.1551 & 1.1503 & & & \\
\hline$T S 2$ & -94.6723976 & -94.7917849 & $\mathrm{CN}$ & 1.2251 & 1.2202 & $\mathrm{CNHe}$ & 137.5 & 141.4 \\
\hline \multirow[t]{2}{*}{$\mathrm{CN}(\mathrm{H}) \mathrm{He}^{2+}$} & & & $\mathrm{NHe}$ & 1.5910 & 1.5247 & $\mathrm{NCH}$ & 84.8 & 78.7 \\
\hline & & & $\mathrm{NH}$ & 1.7186 & 1.6234 & & & \\
\hline$T S 3$ & -94.6661576 & -94.8294050 & $\mathrm{CN}$ & 1.2198 & 1.2202 & $\mathrm{NCHe}$ & 153.2 & 150.8 \\
\hline \multirow[t]{2}{*}{$\mathrm{CN}(\mathrm{H}) \mathrm{He}^{2+}$} & & & $\mathrm{CH}$ & 1.3123 & 1.2821 & $\mathrm{NCH}$ & 75.3 & 80.2 \\
\hline & & & $\mathrm{CHe}$ & 1.1551 & 1.1392 & & & \\
\hline
\end{tabular}

a Total electronic energies are in hartree.

${ }^{\mathrm{b}}$ Bond lengths are in Angstrom. Bond angles are in degrees.

Table 3. Calculated total energies, in $\mathrm{kJ} \mathrm{mol}^{-1}$, associated with the structures shown in Figure 1 relative to the most stable structure, the linear configuration $L$.

\begin{tabular}{lrccrrr}
\hline Energy & \multicolumn{1}{c}{ MP2 } & CCSD/MP2 & CCSD $(\mathrm{T}) / \mathrm{MP} 2$ & CCSD $(\mathrm{T})$ & CASSCF & CASPT2 \\
\hline$E(L)$ & 0.0 & 0.0 & 0.0 & 0.0 & 0.0 & 0.0 \\
$E(N)$ & 250.4 & 210.5 & 210.2 & 205.9 & 208.5 & 212.5 \\
$E(T 1)$ & 322.4 & 236.3 & 245.8 & 246.0 & 229.2 & 254.2 \\
$E(T 2)$ & 387.2 & 297.6 & 308.7 & 307.5 & 313.4 & 319.9 \\
$E(T S 1)$ & 360.4 & 274.9 & 284.7 & 284.8 & 262.4 & 293.7 \\
$E(T S 2)$ & 461.6 & 429.9 & 388.4 & 378.9 & 363.0 & 379.5 \\
$E(T S 3)$ & 337.2 & 268.9 & 271.2 & 278.8 & 278.8 & 280.7 \\
\hline
\end{tabular}

Table 4. Reaction paths between the non-linear structure $N$ and the trigonal pyramidal structures $T 1$ and $T 2$. There are three transition states, $T S 1, T S 2$ and $T S 3$, which correspond to the migration of the $\mathrm{H}$ or $\mathrm{He}$ atom from $\mathrm{CN}$ to $\mathrm{NC}$. Energies are given in $\mathrm{kJ}$ $\mathrm{mol}^{-1}$.

\begin{tabular}{lcccrrr}
\hline Path & MP2 & CCSD/MP2 & CCSD $(\mathrm{T}) / \mathrm{MP} 2$ & $\mathrm{CCSD}(\mathrm{T})$ & CASSCF & CASPT2 \\
\hline$N \longrightarrow T S 1$ & 110.0 & 64.4 & 74.5 & 78.8 & 53.9 & 81.2 \\
$N \longrightarrow T S 2$ & 211.2 & 219.4 & 178.2 & 173.0 & 154.5 & 167.0 \\
$L \longrightarrow T S 3$ & 337.2 & 268.9 & 271.2 & 278.8 & 278.8 & 280.7 \\
$T S 1 \longrightarrow T 1$ & -38.0 & -38.6 & -38.9 & -38.8 & -33.2 & -39.5 \\
$T S 2 \longrightarrow T 2$ & -74.4 & -132.3 & -79.7 & -71.5 & -49.6 & -60.0 \\
$T S 3 \longrightarrow T 1$ & -14.8 & -32.6 & -25.4 & -32.8 & -49.5 & -26.5 \\
\hline
\end{tabular}

lated:

$$
\begin{array}{r}
L \longrightarrow \mathrm{HeC}^{+}\left({ }^{2} \Pi\right)+\mathrm{NH}^{+}\left({ }^{2} \Pi\right) \\
N \longrightarrow \mathrm{HeN}^{+}\left({ }^{1} \Sigma\right)+\mathrm{CH}^{+}\left({ }^{1} \Sigma\right) \\
T 1 \longrightarrow \mathrm{CN}^{+}\left({ }^{1} \Sigma\right)+\operatorname{HeH}^{+}\left({ }^{1} \Sigma\right) \\
T 2 \longrightarrow \mathrm{CN}^{+}\left({ }^{1} \Sigma\right)+\operatorname{HeH}^{+}\left({ }^{1} \Sigma\right)
\end{array}
$$

For these calculations the CASSCF and CASPT2 models were employed. Three additional orbitals were included in the active space. The results of these calculations 
[24]J. Karwowski and I. Shavitt, in Handbook of Molecular Physics and Quantum Chemistry, volume 2, Molecular Electronic Structure, ed: S. Wilson, P.F. Bernath and R. McWeeny, chapter 18, John Wiley, Chichester (2003)

[25]S. Wilson, Electron correlation in molecules, Dover, New York (2007)

[26] J.A. Pople, Rev. Mod. Phys. 71, 1267 (1999)

[27] W.J. Hehre, L. Radom, P. von Schleyer, J.A. Pople: Ab initio Molecular Orbital Theory, John Wiley, Chichester (1986)

[28] L.A. Curtiss, K. Raghavachari, P.C. Redfern, V. Rassolov, J.A. Pople, J. Chem. Phys. 109, 7764 (1998)

[29] L.A. Curtiss, P.C. Redfern, K. Raghavachari, V. Rassolov, J.A. Pople, J. Chem. Phys. 110, 4703 (1999)

[30]D.R. Lide (ed.), CRC Handbook of Chemistry and Physics, $74^{\text {th }}$ edition, CRC Press, Boca Raton (1993)

[31] J.P. Toennies and A.F. Vilesov, Angew. Chem. Int. Ed. 432662 (2004)

[32] J.J. Manley, Nature 115, 337 (1925)

[33]R. Heller, J. Chem. Phys. 9, 154 (1941)

[34] T. Weiske and H. Schwarz, Angew. Chem. Int. Ed. 31183 (1992)

[35] M. Saunders, H.A. Jiménez-Vázquez, R.J. Cross and R.J. Poreda, Science 259, 1428 (1993)

[36] G. Frenking, W. Koch, J. Gauss and D. Cremer, J. Am. Chem. Soc. 110, 8007 (1988)

[37]P. Antoniotti, N. Bronzolino and F. Grandinetti, J. Phys. Chem. A 107, 2974 (2003)

[38] S. Wilson, Adv. Chem. Phys. (1987)

[39]S. Wilson, in Handbook of Molecular Physics and Quantum Chemistry, volume 2, Molecular Electronic Structure, ed: S. Wilson, P.F. Bernath and R. McWeeny, chapter 28, John Wiley, Chichester (2003)

[40]P.P. Bera, K.W. Sattelmeyer, M. Saunders, H.F. Schaefer, and P.R. Schleyer, "Mindless Chemistry", J. Phys. Chem. A 110, 4287 (2006)

[41] G. Karlström, R. Lindh, P.-A. Malmqvist, B. O. Roos, U. Ryde, V. Veryazov, P.-O. Widmark, M. Cossi, B. Schimmelpfennig, P. Neogrady, L. Seijo, Computational Material Science, 28, 222 (2003)

[42] http://www.cmbi.ru.nl/molden/molden.html

[43] M.J. Frisch, G.W. Trucks, H.B. Schlegel, G.E. Scuseria, M.A. Robb, J.R. Cheeseman, J.A. Montgomery, Jr., T. Vreven, K.N. Kudin, J.C. Burant, J.M. Millam, S.S. Iyengar, J. Tomasi, V. Barone, B. Mennucci, M. Cossi, G. Scalmani, N. Rega, G.A. Petersson, H. Nakatsuji, M. Hada, M. Ehara, K. Toyota, R. Fukuda, J. Hasegawa, M. Ishida, T. Nakajima, Y. Honda, O. Kitao, H. Nakai, M. Klene, X. Li, J.E. Knox, H.P. Hratchian, J.B. Cross, V. Bakken, C. Adamo, J. Jaramillo, R. Gomperts, R.E. Stratmann, O. Yazyev, A.J. Austin, R. Cammi, C. Pomelli, J.W. Ochterski, P.Y. Ayala, K. Morokuma, G.A. Voth, P. Salvador, J.J. Dannenberg, V.G. Zakrzewski, S. Dapprich, A.D. Daniels, M.C. Strain, O. Farkas, D.K. Malick, A.D. Rabuck, K. Raghavachari, J.B. Foresman, J.V. Ortiz, Q. Cui, A.G. Baboul, S. Clifford, J. Cioslowski, B.B. Stefanov, G. Liu, A. Liashenko, P. Piskorz, I. Komaromi, R.L. Martin, D.J. Fox, T. Keith, M.A. Al-Laham, C.Y. Peng, A. Nanayakkara, M. Challacombe, P.M.W. Gill, B. Johnson, W. Chen, M.W. Wong, C. Gonzalez, and J.A. Pople, GAussian 03, Gaussian, Inc., Wallingford CT, 2004.

[44]T.J. Lee, J.E. Rice, G.E. Scuseria and H.F. Schaefer, Theor. Chim. Acta 75, 81 (1989)

[45]T.J. Lee and P.R. Taylor, Int. J. Quantum Chem. 23, 199 (1989)

[46]T.H. Dunning, Jr. J. Chem. Phys. 90, 1007 (1989) 


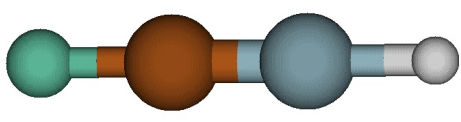

(a)

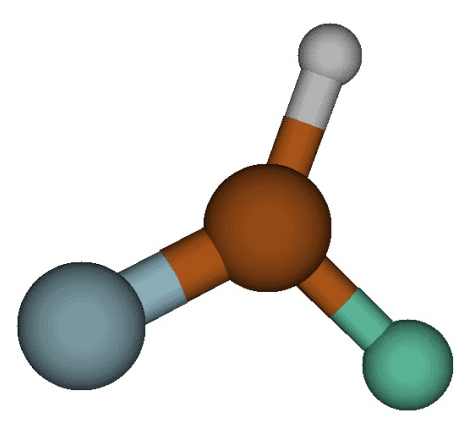

(c)

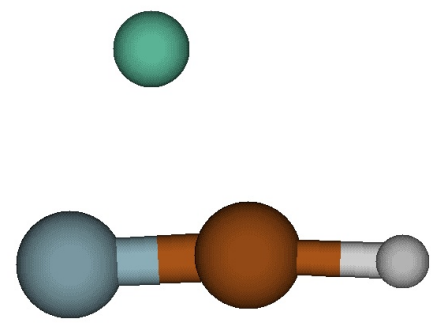

(e)

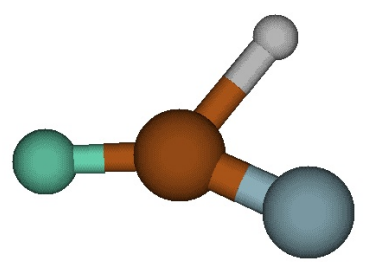

(g)

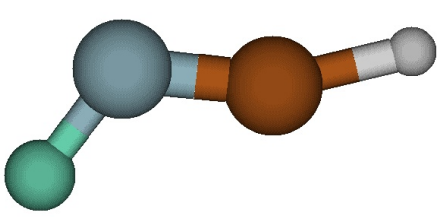

(b)

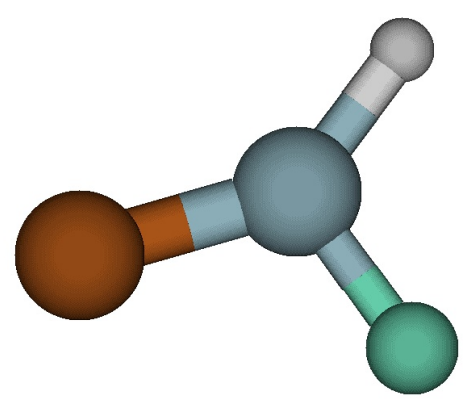

(d)

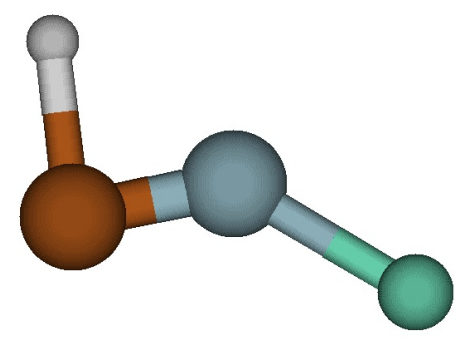

(f)

Figure 1. Geometries of stationary points on the potential energy surface of the $\mathrm{HeCNH}^{2+}$ dication: (a) linear $L$ : $\mathrm{HeCNH}^{2+}$; (b) non-linear $N$ : $\mathrm{HeNCH}^{2+}$;

(c) trigonal pyramidal $T 1: \mathrm{NCHeH}^{2+}$; (d) trigonal pyramidal $T 2: \mathrm{CNHeH}^{2+}$;

(e) transition state TS1: $(\mathrm{HCN} \ldots \mathrm{He})^{2+}$; (f) transition state TS2: $\mathrm{HCNHe}^{2+}$;

(g) transition state $T S 3: \mathrm{HCNHe}^{2+}$. 


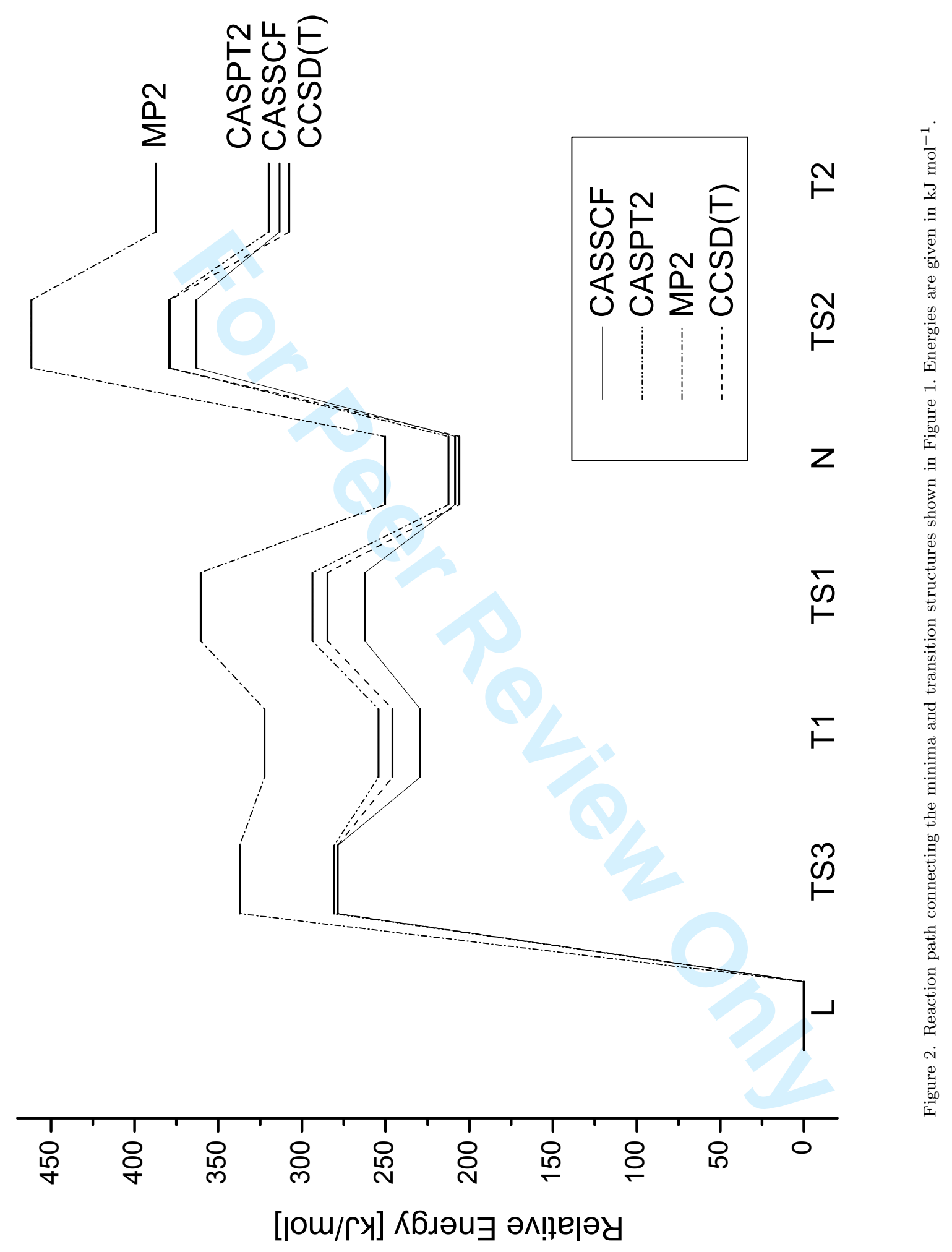




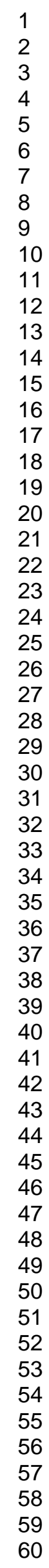

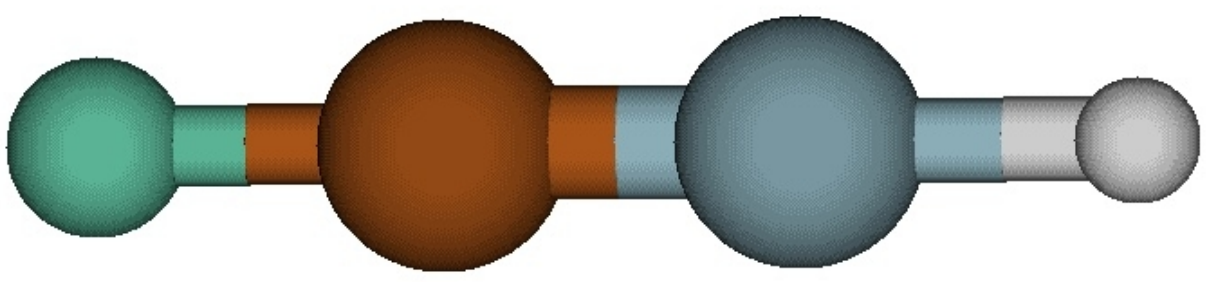

17

19

20

22

23

24

26

27

29

30

32

33

34

35

36

37

38

40

41

42

44

45

46

47

48

49

51

52

53

54

56

57

58

59

60

URL: http://mc.manuscriptcentral.com/tandf/tmph 


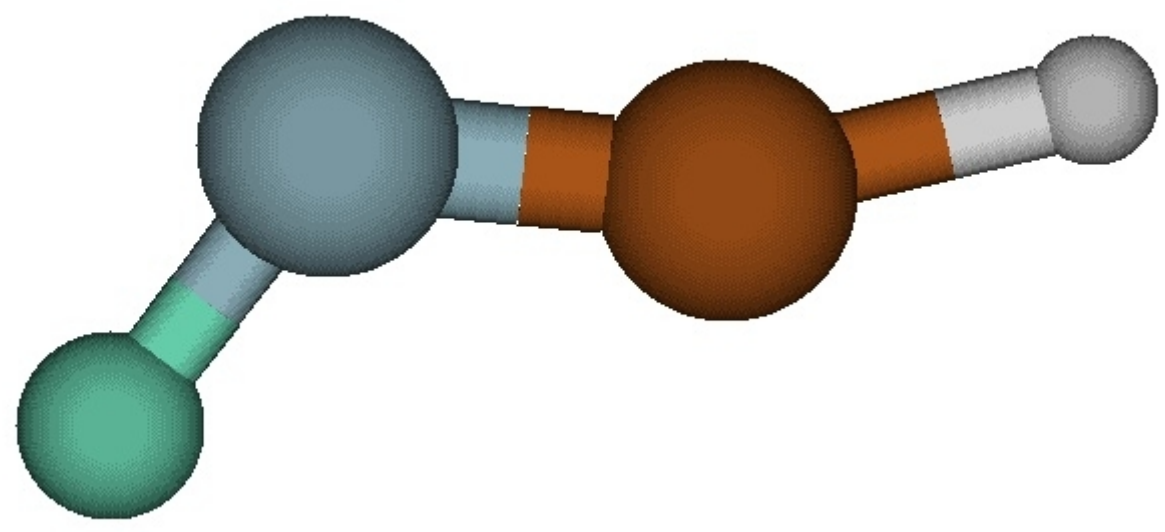




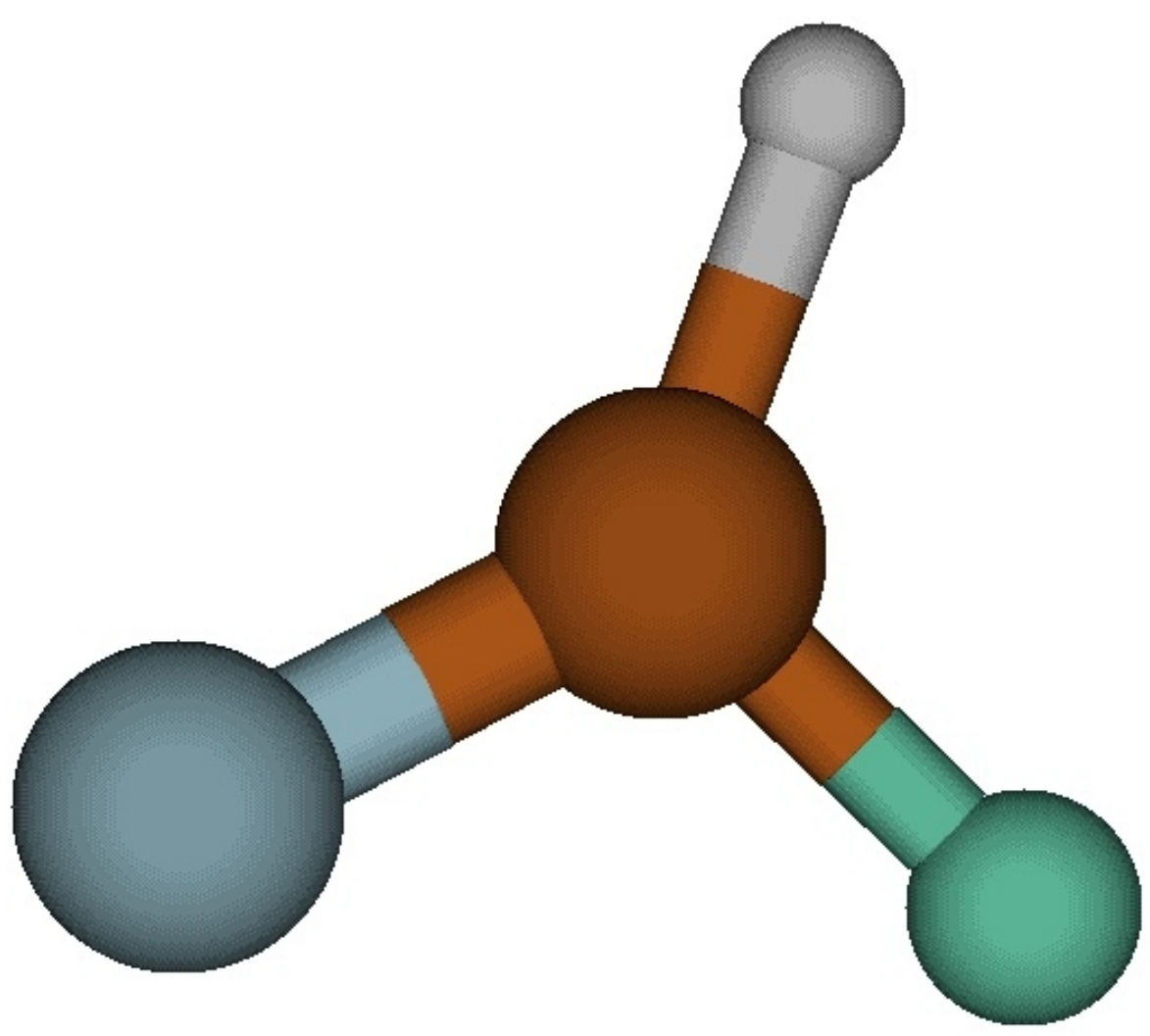




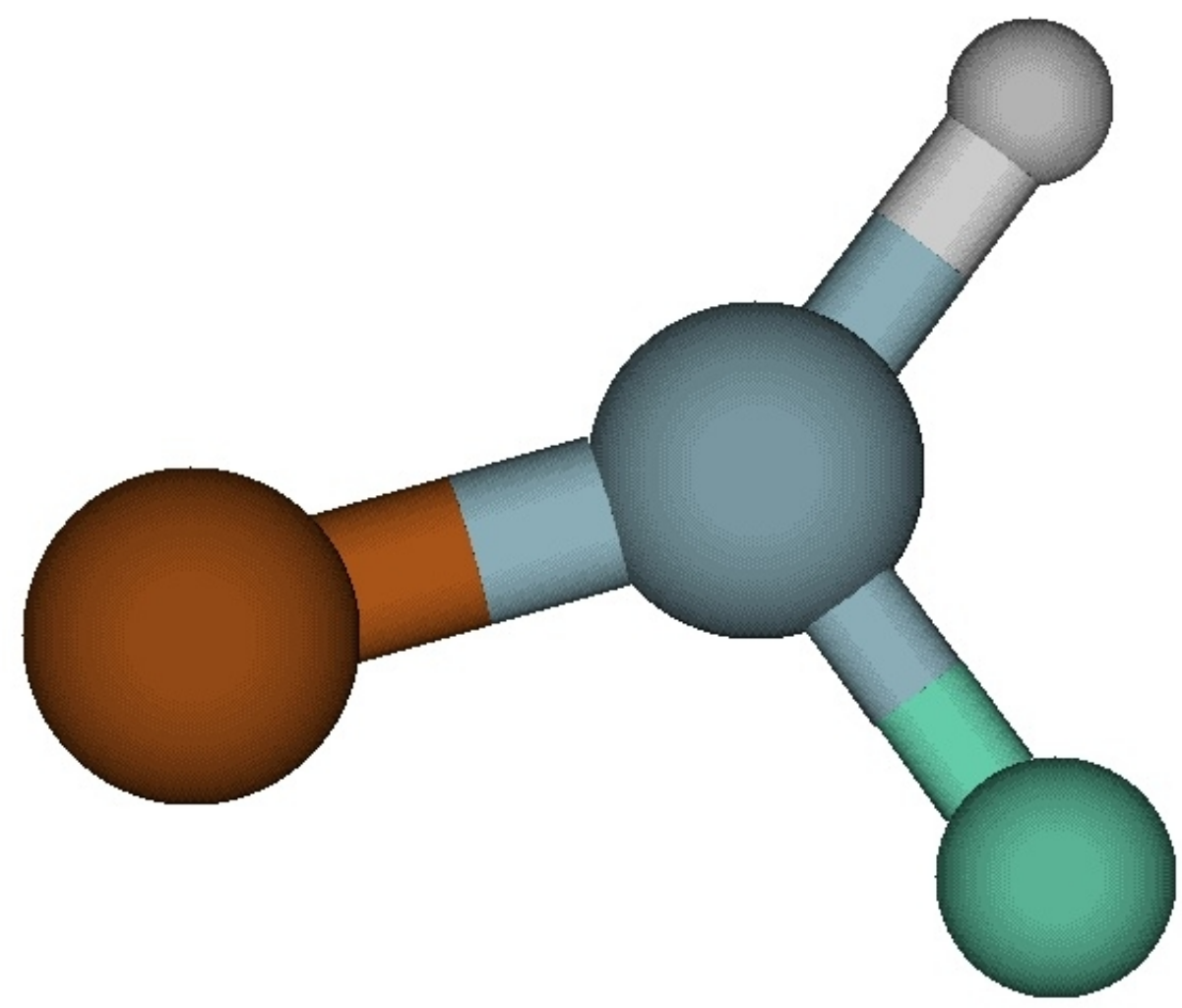

URL: http://mc.manuscriptcentral.com/tandf/tmph 


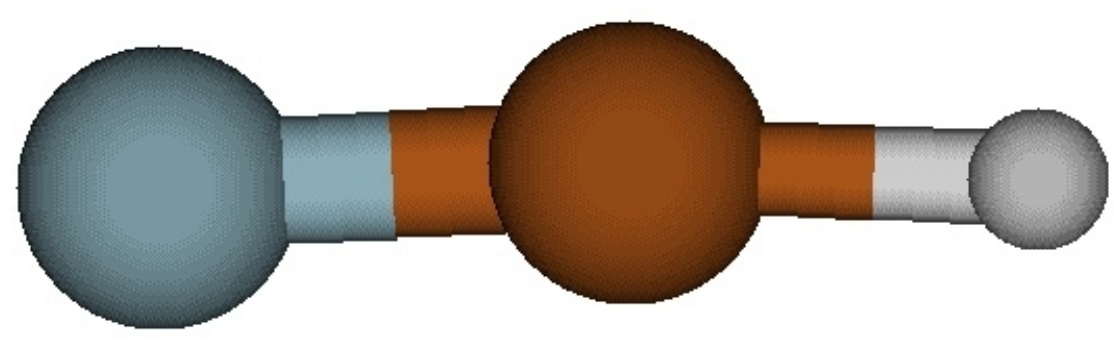


Molecular Physics

Page 16 of 18

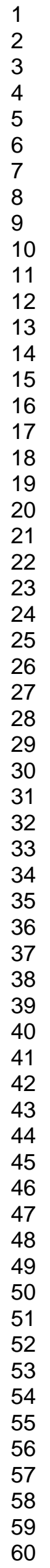




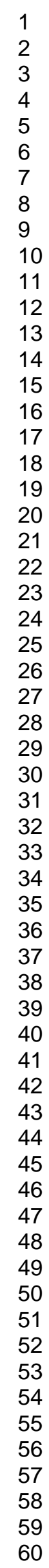

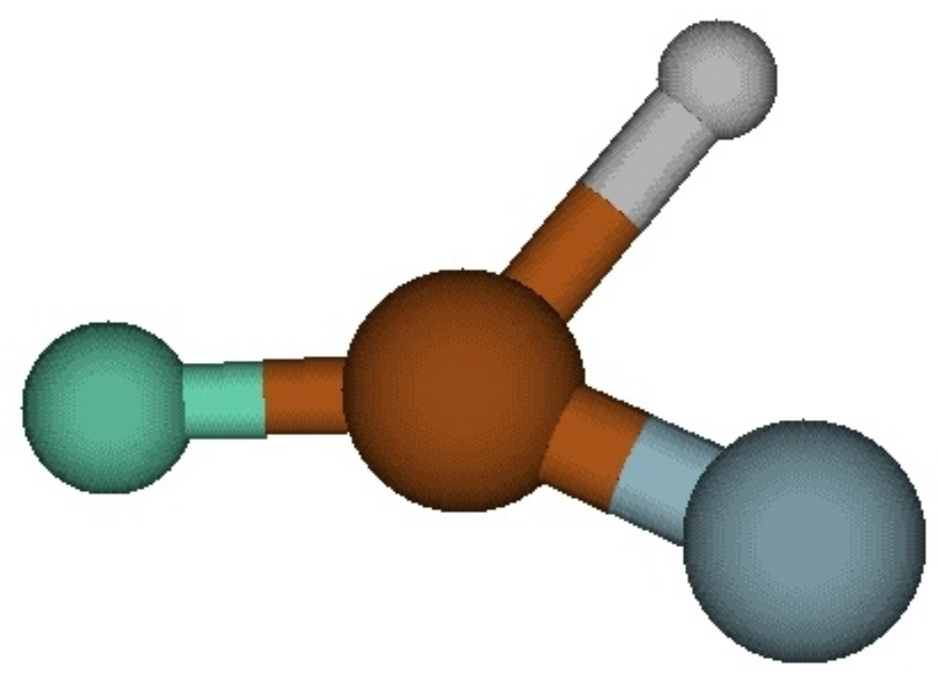

$150 \times 132 \mathrm{~mm}(96 \times 96 \mathrm{DPI})$

URL: http://mc.manuscriptcentral.com/tandf/tmph 


1
2
3
4
5
6
7
8
9
10
11
12
13
14
15
16
17
18
19
20
21
22
23
24
25
26
27
28
29
30
31
32
33
34
35
36
37
38
39
40
41
42
43
44
45
46
47
48
49
50
51
52
53
54
55
56
57
59
60

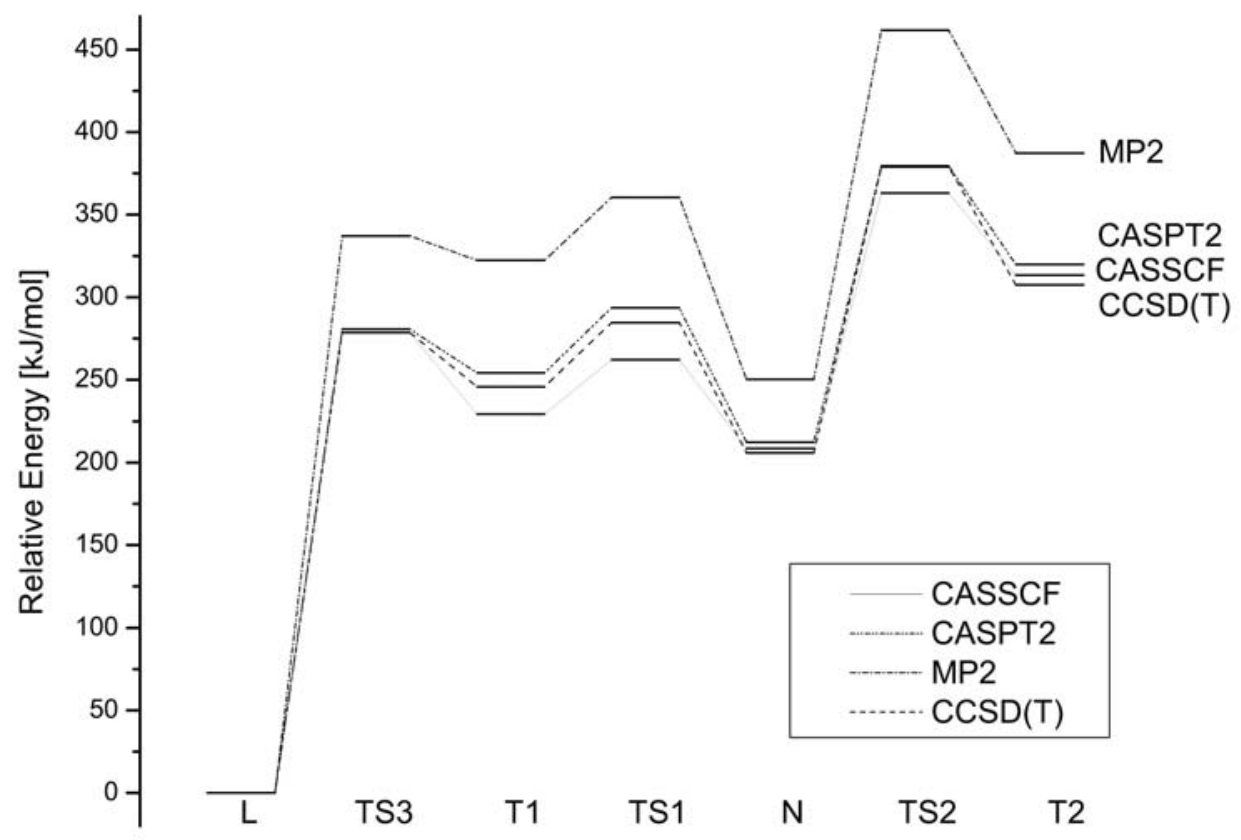

$288 \times 202 \mathrm{~mm}(600 \times 600 \mathrm{DPI})$

URL: http://mc.manuscriptcentral.com/tandf/tmph 